\title{
Epidermal Growth Factor-Urogastrone Causes Vasodilatation in the Anesthetized Dog
}

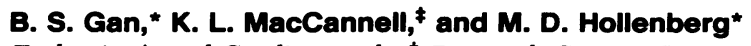 \\ Endocrine* and Cardiovascular ${ }^{\ddagger}$ Research Groups, Department of Pharmacology and Therapeutics, \\ Faculty of Medicine, University of Calgary, Calgary, Alberta, Canada T2N 4NI
}

\begin{abstract}
Epidermal growth factor-urogastrone (EGF-URO) administered intraarterially was a potent dilator in dog femoral (FEM), superior (cephalic) mesenteric (SMA), celiac (CAC), coronary (COR), carotid (CAR), and renal (REN) vascular beds. The effects of EGF-URO, which exhibited tachyphylaxis, could not be attributed either to recirculating EGF-URO or to the secondary release of other agonists or products of the cyclooxygenase pathway. Two vascular beds (FEM, SMA) showed a high maximum responsiveness to EGF-URO (maximum effect [ $\left.E_{\max }\right]$ $\cong 70 \%$ increase in flow) whereas another group (CAC, COR, CAR, and REN) exhibited lower responsiveness $\left(E_{\max } \cong 20 \%\right.$ ). The $\mathrm{ED}_{\mathbf{5 0}}$ for this effect of EGF-URO was in the range of 0.4 $\mu \mathrm{g}$ (FEM, SMA, CAR, and COR) to $0.9 \mu \mathrm{g}$ (CAC and REN). In isolated dog COR helical strips, EGF-URO did not exhibit either a direct relaxing or a contractile effect. However, preincubation of strips with EGF-URO caused up to a $66 \%$ inhibition of contraction in response to norepinephrine $(1 \mu \mathrm{M})$, with an ED $_{50}$ for EGF-URO of $1 \mathrm{nM}$. This action of EGF-URO also showed marked tachyphylaxis. Our data point to a potential role for EGF-URO (and possibly for the structurally related alphatransforming growth factor) in the regulation of blood flow in vivo.
\end{abstract}

\section{Introduction}

Epidermal growth factor-urogastrone (EGF-URO) ${ }^{1}$ is a mammalian polypeptide of $\sim 6,000$ atomic mass units found in mice, rats, and a variety of other species including dogs and humans (for reviews, see references 1-4). EGF-URO was originally isolated either from male mouse submaxillary glands or from human urine on the basis of the polypeptide's ability to stimulate precocious eyelid opening or incisor eruption in newborn mice or to inhibit gastric acid secretion in dogs. EGF-URO is found in almost all body fluids under normal physiologic conditions (5), but the exact nature of its physiological role, either during development or in the adult, is not clear (5). Although many actions of EGF-URO have now been documented in a variety

\section{Address reprint requests to Dr. Hollenberg. \\ Received for publication 14 July 1986 and in revised form 30 December 1986.}

1. Abbreviations used in this paper: EGF-URO, epidermal growth factorurogastrone; NE, norepinephrine; PSS, physiological salt solution; $\alpha$ TGF, alpha-transforming growth factor.

J. Clin. Invest.

(c) The American Society for Clinical Investigation, Inc.

0021-9738/87/07/0199/08 \$2.00

Volume 80 , July $1987,199-206$ of cell culture systems (these effects range from the stimulation of membrane phosphorylation and DNA synthesis to the augmentation of prostaglandin production), few studies, except for those measuring the inhibition of acid secretion, have been done to document the acute effects of EGF-URO in vivo. We were struck by the work of Scoggins and co-workers (6) who observed that adrenalectomized sheep on a basal replacement steroid infusion were unable to maintain their blood pressure when EGFURO was administered intravenously at a rate of $125 \mu \mathrm{g} / \mathrm{h}$. The fall in blood pressure was attributed to a decrease in total peripheral resistance, accompanied by a compensatory increase in cardiac output and an increase in activity of the renin-angiotensin system. On the basis of this study in sheep, which was the first to indicate that EGF-URO could have an effect on the vasculature, we hypothesized that EGF-URO might play a role in the regulation of blood flow. Our own work (7) and the work of others (8) indicated, however, that EGF-URO can have a potent direct contractile effect on rat smooth muscle strips obtained either from the ileocolic artery (7) or from the aorta (8). To explore the seemingly contradictory actions of EGF-URO on the vasculature, in the study we report here, we have examined the effects of close-arterially administered EGF-URO on regional blood flow in a number of vascular beds (femoral, superior mesenteric, coronary, celiac, carotid, and renal) in the anesthetized dog. Further, we also report results of a study of the effects of EGF-URO in vitro on helical arterial strips, obtained from canine coronary arteries.

\section{Methods}

Materials. Reagents were obtained from the following suppliers and were used without further purification: acetylcholine chloride, histamine dichloride, indomethacin, DL-isoproterenol, diphenhydramine hydrochloride, all from Sigma Chemical Co. (St. Louis, MO); aminophylline from Squibb (Montreal, PQ); burimamide hydrochloride from Smith Kline \& French, (Philadelphia, PA); naloxone hydrochloride from Dupont (Mississauga, ON); DL-propranolol from Ayerst (Montreal, PQ); and sodium pentobarbital from Allen and Hanbury (Toronto, ON). All other chemicals were of reagent grade or better. Indomethacin was solubilized with an equimolar amount of sodium carbonate in $0.9 \%$ (wt/vol) sodium chloride. All drugs were freshly diluted in $0.9 \% \mathrm{NaCl}$ before administration. Mouse EGF-URO, purified from submaxillary glands exactly according to the procedure of Savage and Cohen (9), yielded a single band upon gel electrophoresis in sodium dodecyl sulfate-containing polyacrylamide gels (15\%) under reducing conditions and yielded a single peak upon reverse-phase liquid chromatography ( $\mathrm{C}-18$ column) using an acetonitrile gradient in $0.1 \%$ trifluoroacetic acid. Recombinant human urogastrone, kindly provided by Dr. H. Gregory, ICI Pharmaceuticals, Macclesfield, U.K., yielded a single band upon gel electrophoresis and was fully potent in a cultured cell mitogenesis assay. In a human fibroblast system, the $\mathrm{ED}_{50}$ for the mouse and human EGF-URO routinely used in our laboratory is $\sim 0.25 \mathrm{ng} / \mathrm{ml}(10)$.

Surgical procedures and measurements of blood flow. Mongrel dogs of either sex weighing 16 to $33 \mathrm{~kg}$ were anesthetized with sodium pen- 
tobarbital $(30 \mathrm{mg} / \mathrm{kg}$ i.v.). The animals were immediately intubated and ventilated with room air at $15 \mathrm{ml} / \mathrm{kg}$ per min. Additional pentobarbital was administered, as required, to maintain stable anesthesia. Routinely, the following parameters were continuously monitored as previously described $(11,12)$ and were recorded on a Gould 2800 S recorder (Gould, Inc., Cleveland, $\mathrm{OH}$ ): systemic arterial blood pressure, central venous pressure (Statham P23 DB transducers; Gould, Inc., Oxnard, CA), lead II electrocardiogram, and regional blood flow. All vessels used for monitoring regional blood flow were carefully dissected to avoid injury to the artery and the nerve supply and were fitted with electromagnetic flow probes attached to appropriately calibrated Micron RC 1000 flow meters (Micron Instruments, Los Angeles, CA). To measure coronary flow, the chest of the animal was opened through the fourth left intercostal space and a flow probe was placed around the left anterior descending coronary artery just after the bifurcation of the left circumflex coronary artery. To measure superior mesenteric flow, celiac flow, and renal flow, the abdominal cavity was approached via a midline incision, and flow probes were placed around the appropriate arteries as close as possible to the aorta. To measure carotid flow, a flow probe was placed around the left common carotid artery exposed through a left anterolateral cervical incision. The femoral flow was recorded from probes placed around the left and right femoral arteries exposed at the level of the inguinal fold. After completion of the surgical procedures, the animal was allowed to equilibrate for $60 \mathrm{~min}$. At equilibration, baseline hemodynamic variables were: arterial blood pressure, systolic, $166 \pm 3.5 \mathrm{~mm} \mathrm{Hg}$ (average \pm SEM); arterial blood pressure, diastolic, $128 \pm 3.6 \mathrm{~mm} \mathrm{Hg}$; central venous pressure, $4.2 \pm 0.2 \mathrm{~mm} \mathrm{Hg}$; femoral blood flow, $45 \pm 8 \mathrm{ml} / \mathrm{min}$; mesenteric blood flow, $142 \pm 22 \mathrm{ml} / \mathrm{min}$; celiac flow, $169 \pm 21 \mathrm{ml} / \mathrm{min}$; renal blood flow, $171 \pm 15 \mathrm{ml} / \mathrm{min}$; coronary blood flow, $31 \pm 5 \mathrm{ml} / \mathrm{min}$; and carotid blood flow, $178 \pm 27 \mathrm{ml} / \mathrm{min}$. EGF-URO, purified from male mouse submaxillary glands according to the procedure of Savage and Cohen (9) was administered close-arterially in a standard volume of 1 $\mathrm{ml}$ of $0.9 \% \mathrm{NaCl}$ followed by a $1-\mathrm{ml}$ saline flush. $2-\mathrm{ml}$ saline injections were used as controls. The intraarterial injections of EGF-URO were made using hubless 27 -gauge needles attached to $1-\mathrm{ml}$ syringes by means of polyethylene tubing which had a dead space of $0.1 \mathrm{ml}$. The needles were left in situ, distal to the flow probes. Test doses of EGF-URO $(0.05-$ $5.0 \mu \mathrm{g}$ ) were administered in a random sequence. After each injection, the flow was allowed to return to the baseline value, and was equilibrated for an additional 15-min interval before the administration of the next test dose. Because of interanimal variability, and in keeping with usual practice (13), all flows were normalized by expressing the vascular response to EGF-URO as a percent increase in flow (\%I) relative to the baseline flow value. Test doses of sodium nitroprusside $(0.1 \mu \mathrm{g})$ were used to confirm that the EGF-URO-mediated increases in flow (maximum increase $\cong 70 \%$ ) were well below the maximum responsiveness of the vascular bed ( $>200 \%$ increase in flow caused by nitroprusside).

Effects of systemically administered blocking agents. The effects of a variety of systemically administered blocking agents on the stimulation of blood flow by EGF-URO were evaluated by a previously used protocol $(11,12)$. A test dose of EGF-URO $(1 \mu \mathrm{g})$ was administered close-arterially (femoral artery) both before and after the intravenous administration of each blocking agent. The agents (burimamide, $1 \mathrm{mg} / \mathrm{kg}$; diphenhydramine, $4 \mathrm{mg} / \mathrm{kg}$; atropine, $1 \mathrm{mg} / \mathrm{kg}$; naloxone, $20 \mu \mathrm{g} / \mathrm{kg}$; propranolol, 1 $\mathrm{mg} / \mathrm{kg}$; aminophylline, $10 \mathrm{mg} / \mathrm{kg}$; and indomethacin, $5 \mathrm{mg} / \mathrm{kg}$ ) were routinely administered intravenously in a random sequence that differed for each experiment. The blocking agents were administered slowly while monitoring the vital signs, which were kept within $5 \%$ of control values. The effectiveness of blockade was evaluated by the close-arterial administration of the appropriate agonists. Effective agonist blockade was observed with diphenhydramine (vs. histamine), atropine (vs. acetylcholine), propranolol (vs. isoproterenol), and naloxone (vs. beta endorphin). The doses of aminophylline and indomethacin used are known to be effective inhibitors of purinergic metabolism and cyclooxygenase systems, respectively. The possibility that carryover effects of the blocking agents may have influenced data obtained in the sequential administration protocol was excluded by evaluating the effect of each blocking agent on the response to EGF-URO in animals which had received no other blocking drugs. In these control experiments, each blocking agent was individually tested in two animals; the protocol was unchanged from the sequential blockade experiments outlined above, wherein the response to EGF-URO was measured both before and after the administration of each blocking agent.

In vitro bioassay of canine coronary helical arterial strips. A preliminary survey showed that coronary arterial strips, which were as responsive as femoral-derived strips, provided the most reproducibly responsive tissue. Coronary strips offered the added advantage that the results could be compared with data obtained using material easily obtained at abatoirs from other species (cow, pig, or sheep); such comparative studies are ongoing in our laboratory. Thus, helical strips from the coronary artery were used for this study. Hearts of mongrel dogs of either sex, were obtained immediately after sacrifice. The left anterior descending and left circumflex coronary arteries were carefully dissected and placed in a petri dish containing physiological salt solution (PSS) which was aerated with a mixture of $95 \% \mathrm{O}_{2}$ and $5 \% \mathrm{CO}_{2}$. PSS had the following composition (in millimolar) $\mathrm{NaCl}, 115 ; \mathrm{KCl}, 4.7 ; \mathrm{CaCl}_{2}, 2.5 ; \mathrm{MgCl}_{2}, 1.2 ; \mathrm{NaHCO}_{3}$, $25 ; \mathrm{KH}_{2} \mathrm{PO}_{4}, 1.2$; dextrose, 10.0. Under a dissecting microscope, the arteries were trimmed of fat and adhering tissue. Sections of the arteries, which had an outer diameter between 2.0 and $2.5 \mathrm{~mm}$, were cut into helical strips, $\sim 1.2 \mathrm{~mm}$ in width and $8 \mathrm{~mm}$ in length. Care was taken to avoid stretching of the arteries. The presence of functional endothelium was demonstrated by the relaxation in response to $1 \mu \mathrm{M}$ acetylcholine of strips precontracted with $30 \mathrm{mM} \mathrm{KCl}$ (14). In some experiments, the intimal side of the strips was gently rubbed over wetted filter paper and the loss of intact endothelium was demonstrated by the lack of a relaxing response to acetylcholine. The strips were mounted vertically in a plastic organ bath containing $3 \mathrm{ml}$ of a PSS and propranolol $(1 \mu \mathrm{M})$. In experiments where the preparations were assayed under calcium-free conditions, $\mathrm{CaCl}_{2}$ was omitted and replaced by $1.0 \mathrm{mM}$ EGTA. The bath medium was maintained at $37^{\circ} \mathrm{C}, \mathrm{pH} 7.4$, and was equilibrated with a gas mixture of $95 \% \mathrm{O}_{2}$ and $5 \% \mathrm{CO}_{2}$. A resting tension of $1.5 \mathrm{~g}$ (optimal for the response of the tissue to $\mathrm{KCl}$ or norepinephrine [NE]) was applied to the arterial strips, and the responses were recorded isometrically through force-displacement transducers (Statham UTC2) on a Gould 2400 S recorder. All preparations were equilibrated for $60 \mathrm{~min}$ before starting the experiments. Drugs were added directly to the bath and concentrations were calculated accordingly.

\section{Results}

Effects on femoral blood flow. In preliminary experiments, it was established that close-arterially administered EGF-URO caused an increase in blood flow in all arterial beds tested (femoral, superior mesenteric, coronary, celiac, carotid, and renal), without concomitant changes in systemic blood pressure, central venous pressure, or electrocardiogram. In that perfusion pressure did not change, an increase in blood flow was a direct measure of a decrease in regional vascular resistance. The femoral arterial bed was selected for a detailed study because of its high responsiveness and because of the availability of two comparable beds in a single animal. As illustrated in Fig. 1 (upper trace), the response to EGF-URO was slightly delayed, reaching a maximum within 2-6 min and persisting for up to $12-18 \mathrm{~min}$. The response to EGF-URO exhibited marked tachyphylaxis, in that a second dose of EGF-URO, administered at a time when the response to the first dose had diminished by $>50 \%$, did not cause a sustained elevation of flow, as did the first dose (Fig. 1, middle trace). If tachyphylaxis were not present, one would have expected to observe an appreciable increase in flow $1.5 \mathrm{~min}$ after the second dose of EGF-URO; instead, at $1.5 \mathrm{~min}$ after the second dose of EGF-URO (Fig. 1, middle trace) the blood flow was returning towards the baseline value. Control experiments indicated that the maximum increase in flow caused by EGF- 

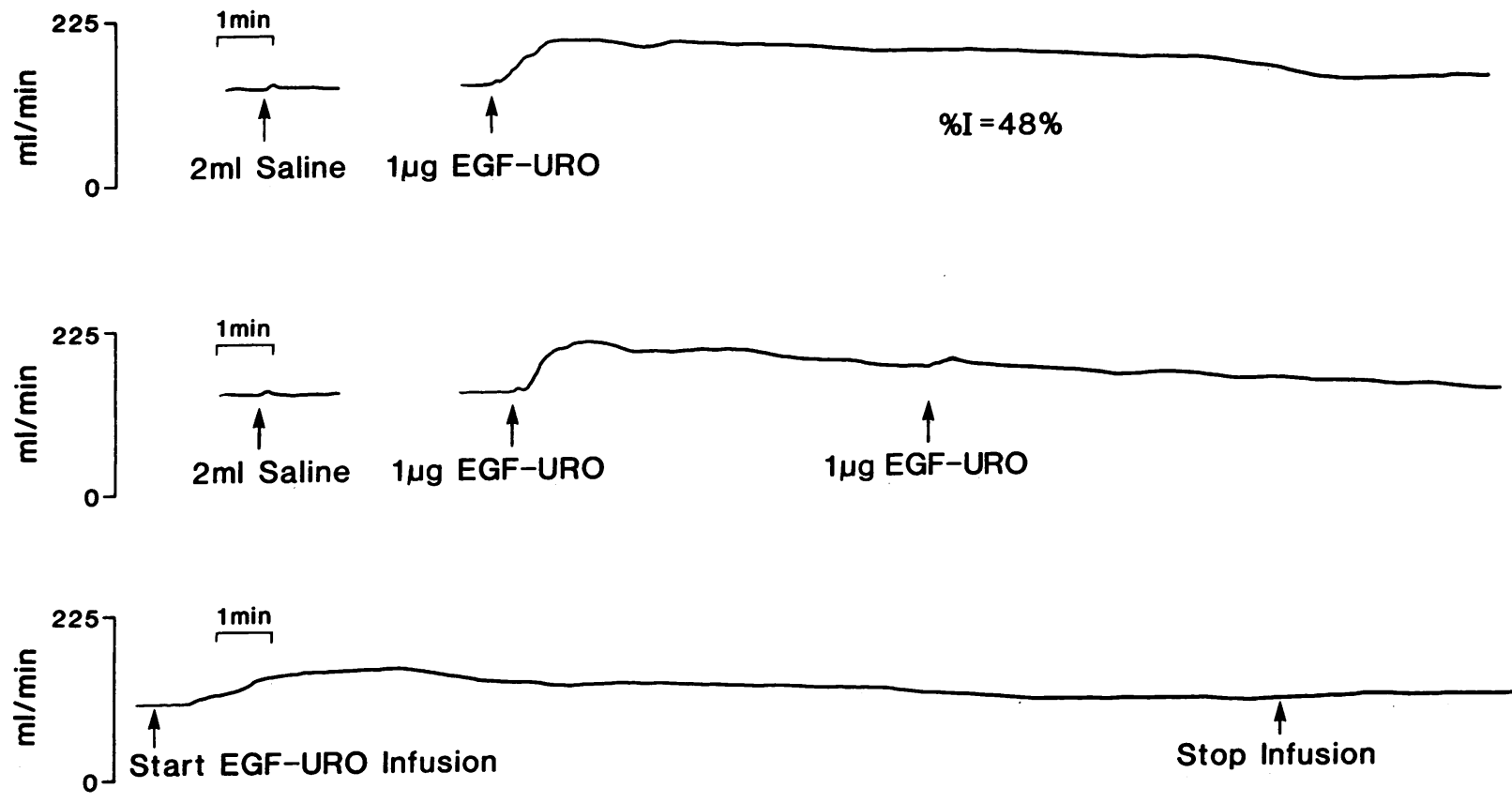

Figure 1. Effect of EGF-URO on blood flow in the femoral vascular bed. (Upper trace) Typical tracing of the flow response to close-arterial administration of EGF-URO in the femoral vascular bed. The response is slightly delayed and may last up to $18 \mathrm{~min}$. The response is expressed as a percent increase in flow (\%I) from the baseline value. (Middle trace) Tachyphylaxis phenomenon in the femoral vascular

URO was well below the overall maximum responsiveness of the femoral bed, as indicated by a test dose of either sodiumnitroprusside or isoproterenol. When EGF-URO was administered by a continuous close-arterial infusion $(1 \mu \mathrm{g} / \mathrm{min}$ for 20 $\mathrm{min}$ in a volume of $0.5 \mathrm{ml} / \mathrm{min}$ ), the initial increase in flow returned to the baseline level within $20 \mathrm{~min}$, despite the continuous infusion of EGF-URO (Fig. 1, lower trace). $15 \mathrm{~min}$ after stopping the EGF-URO infusion, a subsequent test dose of EGFURO $(1 \mu \mathrm{g})$ caused the same increase in flow as the initial test dose. Thus, despite the problem of tachyphylaxis, it was possible, with appropriate dose intervals (30 $\mathrm{min})$, to obtain a dose-response curve for the stimulatory effect of EGF-URO on femoral blood flow (Fig. 2). The hyperbolic dose-response curve was readily linearized by plotting $1 /[$ EGF-URO $(\mu \mathrm{g})]$ vs. $1 /[\%$ increase in flow] (equivalent to a Lineweaver-Burke plot for the analysis of enzyme kinetics). From the slope and intercept of the linearized plot (Fig. 3), it was possible to calculate an $\mathrm{ED}_{50}$ of $0.40 \mu \mathrm{g} /$ dose for EGF-URO (equivalent to the $K_{\mathrm{m}}$ of the Lineweaver-Burke plot) and a maximum effect $\left(E_{\max }\right)$ for EGF-URO of a $70 \%$ increase in flow (equivalent to the $V_{\max }$ of the enzyme kinetic plot).

The possibility existed that intraarterially administered EGFURO might recirculate to act systemically and to release a vasoactive substance elsewhere, which could then cause the observed increase in blood flow. Thus, in control experiments, blood flow was measured simultaneously in both the right and left femoral beds, and EGF-URO $(1 \mu \mathrm{g})$ was injected into one of the beds. Although the arterial bed treated with EGF-URO responded with a robust increase in flow, no change in flow was detected in the contralateral arterial bed. This result was in keeping with other experiments, wherein the intravenous ad- ministration of a bolus test dose of EGF-URO $(10 \mu \mathrm{g})$ had no effect on blood flow monitored either in the femoral arterial bed, or in other arterial beds examined (celiac, renal, or superior mesenteric). Thus, our control experiments confirmed that the effects of close-arterially administered EGF-URO on blood flow

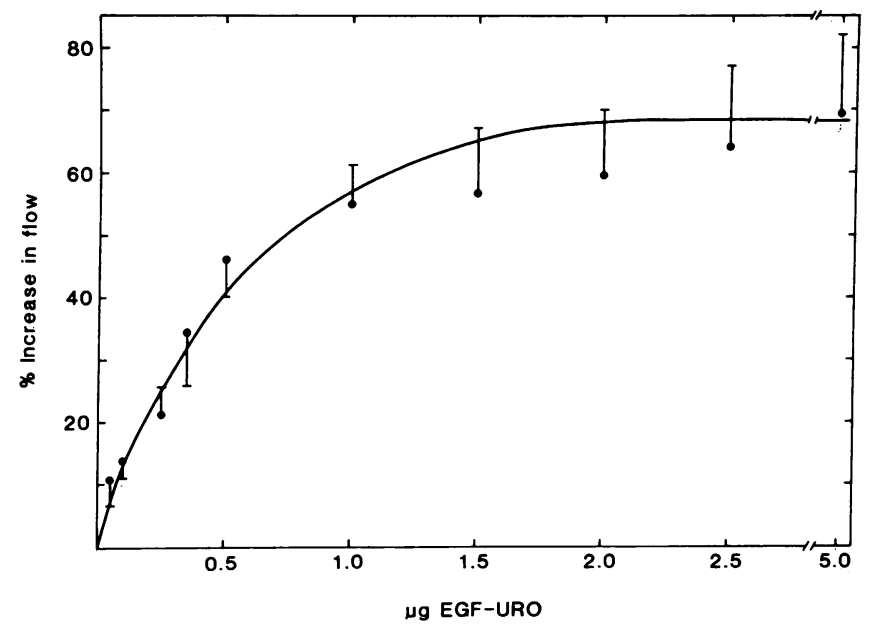

Figure 2. Dose-response curve for the EGF-URO-mediated increase in blood flow in the femoral vascular bed. Various doses of EGF-URO were administered in a random order into the femoral vascular bed. EGF-URO was injected directly into the vessel just distally to the flow probe. The responses to EGF-URO were expressed as the percent increase in flow from the baseline value. Each point with error bars represents the mean \pm standard error of values obtained in 8-12 experiments done in separate animals. 


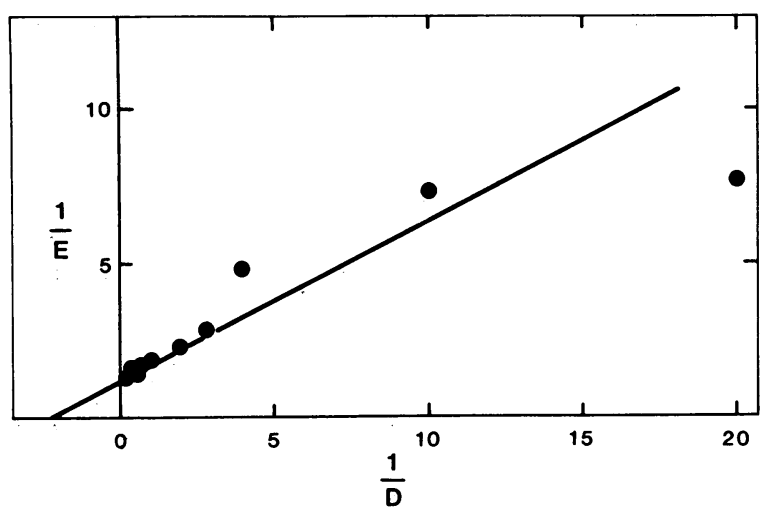

Figure 3. Double reciprocal plot of the response to EGF-URO in the femoral arterial bed. The hyperbolic dose-response curve in Fig. 2 was linearized using a double reciprocal plot. 1/[dose EGF-URO $(\mu \mathrm{g})$ ] (1/ $D)$ vs. $10^{2} /[\%$ increase in flow $(1 / E)$. Linear regression analysis of the straight line $(r=0.98)$ yielded from the reciprocal of the $y$-intercept, $E_{\max } \cong 70 \%$ and from the reciprocal of the $x$-intercept, $\mathrm{ED}_{50} \cong 0.4 \mu \mathrm{g}$.

were not due to systemic production of some other vasoactive substance.

Effects of blocking agents. With attention focussed on the effects of EGF-URO on femoral blood flow, we evaluated the action of a variety of pharmacologic blocking agents, as summarized in Table I. The effectiveness of sympathetic, cholinergic, and histaminergic blockade was assessed by the close-arterial administration of test doses of isoproterenol $(0.1 \mu \mathrm{g})$, acetylcholine $(0.1 \mu \mathrm{g})$, and histamine $(0.1 \mu \mathrm{g})$ both before and after the intravenous administration of the appropriate blocking agents. None of the blocking agents tested (propranolol, atropine, diphenhydramine, burimamide, aminophylline, naloxone, and indomethacin) significantly affected the ability of EGF-URO to increase blood flow either in the experiments where the blocking

Table I. Effects of Blocking Agents on the Response to EGF-URO in the Femoral Vascular Bed

\begin{tabular}{llr}
\hline Blocker & \multicolumn{2}{l}{ Percent increase in flow } \\
\hline & $\%$ & $(n)$ \\
None & $51.0 \pm 10.2$ & $(13)$ \\
Propranolol & $46.2 \pm 4.8$ & $(11)$ \\
Atropine & $53.4 \pm 9.7$ & $(9)$ \\
Burimamide & $53.6 \pm 12.2$ & $(11)$ \\
Diphenhydramine & $48.1 \pm 8.1$ & $(13)$ \\
Aminophylline & $45.0 \pm 10.6$ & $(8)$ \\
Naloxone & $42.9 \pm 9.6$ & $(12)$ \\
Indomethacin & $49.7 \pm 6.2$ & $(11)$
\end{tabular}

The ability of a variety of blocking agents to alter the increase in femoral vascular blood flow caused by EGF-URO $(1 \mu \mathrm{g})$ was tested as outlined in Methods. The response to EGF-URO (percent increase in flow) was measured either before (no blocker) or after the administration of a variety of agents. Values obtained from either a sequential blockade protocol or from a single blockade experiment were pooled. Values represent the mean response to EGF-URO ( \pm standard error) observed either in the absence (no blocker) or presence of the indicated blocking agents. The values in parentheses represent the number of observations, made with each agent. agents were administered in a sequential fashion in a single dog or in experiments where the blocking agents were tested individually in separate animals. In contrast, antagonists did block the actions of appropriate agonists.

Effect of EGF-URO in other vascular beds. Based on our results obtained with the femoral vascular bed, we studied in more detail the action of EGF-URO on blood flow in a variety of other arterial beds: superior mesenteric, celiac, coronary, carotid, and renal. For each arterial bed, it was possible to obtain dose-response curves like the one obtained for the femoral bed (Fig. 4). As summarized in Table II, linearizing the dose-response curves by the use of a double-reciprocal plot yielded, as for the femoral bed, an $\mathrm{ED}_{50}$ and $E_{\max }$ for each arterial bed examined. In all arterial beds examined, the maximum increase in flow caused by EGF-URO was well below the increase in flow that could be obtained with vasodilators such as isoproterenol and nitroprusside. The dose-response data indicated that, although EGF-URO caused an increase in flow in all arterial beds tested, there appeared to be two groups of vascular beds, one of which (femoral and superior mesenteric) exhibited high responsiveness ( $E_{\max } \cong 70 \%$ ) and one of which (celiac, coronary, carotid, and renal) exhibited low responsiveness $\left(E_{\max } \cong 20 \%\right)$. In terms of sensitivity, the celiac and renal beds $\left(E_{50} \cong 0.9 \mu \mathrm{g}\right)$ appeared to be less sensitive than the femoral, superior mesenteric, carotid, and coronary beds $\left(\mathrm{ED}_{\mathrm{s0}}, 0.4 \mu \mathrm{g}\right)$.

Effects of EGF-URO on canine coronary arterial helical strips in vitro. In the study of canine coronary artery helical strips in vitro, EGF-URO did not cause either a direct contraction or a relaxation, but it did modify the response to NE (Fig. 5). The contractile response of propranolol-treated strips to $1.0 \mu \mathrm{M} \mathrm{NE}$ (Fig. $5 A$ ) was highly reproducible once the preparation had stabilized (the contraction shown in Fig. $5 A$, represents exactly the response to three previous test doses of NE). If these strips were then preincubated for $10 \mathrm{~min}$ with EGF-URO, the subsequent response to NE was markedly inhibited (Fig. 5 B). The response to $1 \mu \mathrm{M} \mathrm{NE}$ in the absence of EGF-URO was $\sim 50 \%$ of the maximum NE-mediated contraction, which was obtained

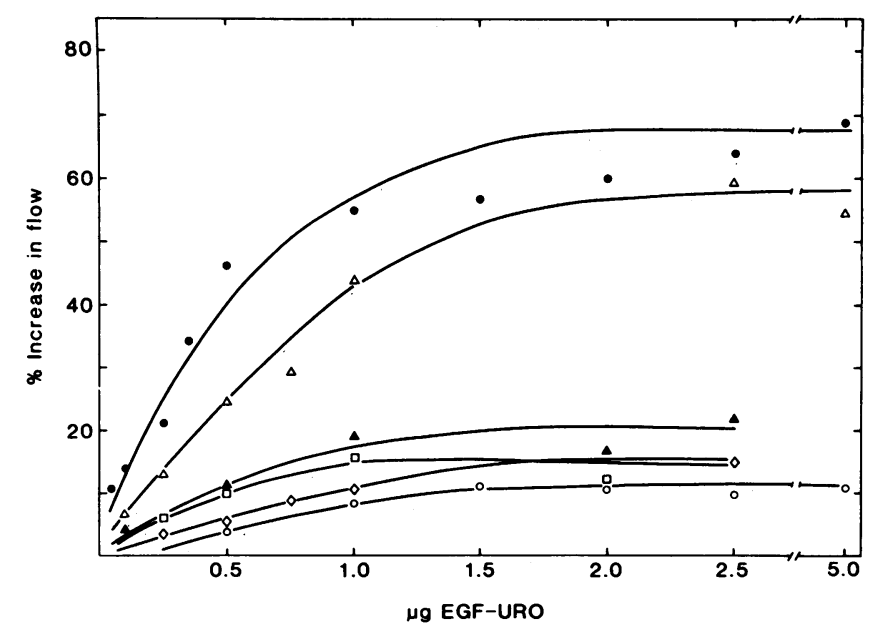

Figure 4. Dose-response curves for EGF-URO in the various arterial beds tested. (Solid circles) femoral $(n=8-12)$; (open triangles) superior mesenteric $(n=9)$; (solid triangles) carotid $(n=4)$; (open diamonds) celiac ( $n=5)$; (open squares) coronary $(n=5) ;$ (open circles) renal $(n=5)$. Data were obtained as described in the text. For the sake of clarity, error bars like the ones shown in Fig. 2 were omitted. 

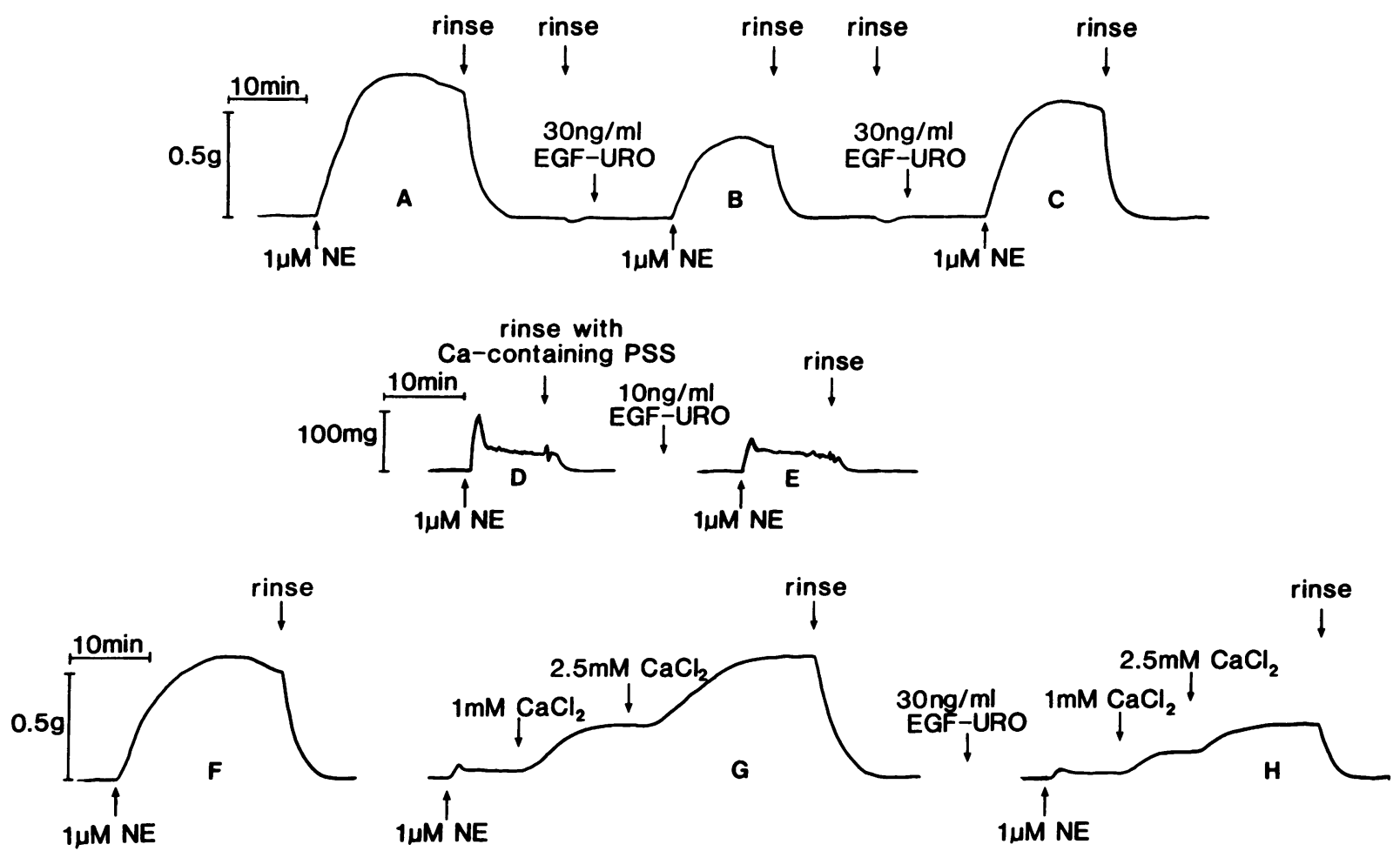

Figure 5. Effects of EGF-URO in vitro in coronary arterial strips. Coronary helical arterial strips were prepared as described in the text. ( $U p$ per trace) Strips were repetitively contracted (four or more times) with $1 \mu \mathrm{M} \mathrm{NE}$, in the presence of $1 \mu \mathrm{M}$ propranolol, until a reproducible contraction was obtained. Tracing $A$ is the same as the response to at least three previous test doses of NE. This contraction was taken as $100 \%(100 \%=0.61 \pm 0.06 \mathrm{~g}, n=30)$. Pretreatment with EGF-URO for $10 \mathrm{~min}$ caused a markedly attenuated response to $1 \mu \mathrm{M}$ NE $(B)$. Subsequent repetition of the pretreatment procedure revealed that the strips acquired a significant tachyphylaxis for the effects of EGF-URO, in that a second $(C)$ or third treatment (not shown) did not cause the same inhibition as the initial treatment. (Middle traces) Typical tracing of experiments in which the strips were incubated for $10 \mathrm{~min}$ in calcium-free medium prior to the addition of NE. Characteristically, the strips showed a reproducible initial phasic and a subsequent tonic responses to $1 \mu \mathrm{M}$ NE. Shown are the phasic contractions in Ca-free medium in response to NE, before treatment with EGF-URO $(D)$, and after treatment with EGF-URO $(E)$. (Lower traces) Typical tracing of experiments in which the response was made dependent on the addition of $\mathrm{Ca}$. Shown is a representative reproducible NE-mediated contraction in the presence of $2.5 \mathrm{mM} \mathrm{Ca}(F)$. The NE-mediated contraction was then made dependent on the addition of $\mathrm{Ca}(G)$ (note the same magnitude as if $\mathrm{Ca}$ had been present $\mathrm{NE}$ administration). The Ca-dependent contraction was then observed after pretreating the tissue for $10 \mathrm{~min}$ with EGF-URO $(H)$.

min ("Ca loading"); this procedure was repeated until a reproducible contraction was obtained. In Ca-free medium the response to $1 \mu \mathrm{M}$ NE showed, as is described for other arteries (14), an initial phasic component, followed by a stable tonic plateau (Fig. $5 \mathrm{D}$ ). The magnitude of the reproducible phasic contraction was taken as baseline value $(0.12 \pm 0.02 \mathrm{~g}, n=5)$. Preincubation with $10 \mathrm{ng} / \mathrm{ml}$ (1.6 nM) EGF-URO caused an inhibition of the phasic component of the NE-mediated contraction in Ca-free medium of $50.2 \pm 6.5 \%(n=5)$ (Fig. $5 E$ ). In some experiments, contraction was made dependent on the addition of $\mathrm{Ca}$ to the organ bath. First the strips were treated to obtain a reproducible response to $1 \mu \mathrm{M} \mathrm{NE}$ in a $2.5 \mathrm{mM} \mathrm{Ca-}$ containing PSS (Fig. $5 F$ ). Subsequently, the strips were incubated in Ca-free medium for $10 \mathrm{~min}$. The addition of $1 \mu \mathrm{M} \mathrm{NE}$ showed the normal response to $\mathrm{NE}$ in a Ca-free medium (see Fig. $5 \mathrm{D}$ ). We then added $\mathrm{Ca}$. The response upon adding $\mathrm{Ca}$ (up to $2.5 \mathrm{mM}$ ) was the same in magnitude as if $\mathrm{Ca}$ had been present at $2.5 \mathrm{mM}$ in the medium before NE administration (Fig. $5 \mathrm{G}$ ). The strips were then Ca-loaded for $20 \mathrm{~min}$ and again incubated for $10 \mathrm{~min}$ in Ca-free medium, which also contained $30 \mathrm{ng} / \mathrm{ml}$ EGF-URO; NE ( $1 \mu \mathrm{M})$ was then added. Under these circumstances, the response upon adding $\mathrm{Ca}$ was much lower than the 


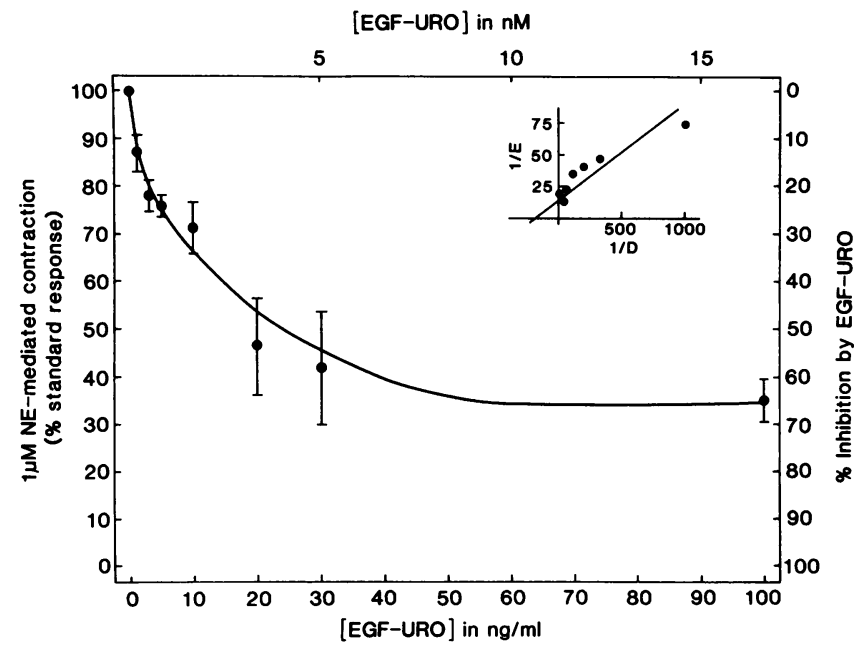

Figure 6. Dose-response curve for the inhibitory effect of EGF-URO on the NE-mediated contraction of coronary helical arterial strips. The strips were treated to obtain a reproducible contraction in response to $1 \mu \mathrm{M}$ NE. This control contraction was taken as $100 \%$ $(100 \%=0.61 \pm 0.06 \mathrm{~g}, n=30)$. Then the strips were pretreated with EGF-URO for $10 \mathrm{~min}$ and again contracted with $1 \mu \mathrm{M}$ NE. Each strip was treated only once with EGF-URO to avoid the problem of tachyphylaxis. Results are expressed as a percentage of the control contraction (left side) or as a percent inhibition of this control contraction (right side). Each point in the figure represents the mean $\pm \mathrm{SE}$ of four to five experiments. (Inset) Linear conversion of the hyperbolic doseresponse curve. The $x$-axis represents $10^{3} /[\operatorname{EGF}-\mathrm{URO}(\mathrm{ng} / \mathrm{ml})](1 / D)$ and the $y$-axis represents $10^{3} /[\%$ Inhibition by EGF-URO] $(1 / E)$. Linear regression $(r=0.96)$ using this double reciprocal plot yielded an estimated maximum inhibition $\cong 66 \%$ with an $\mathrm{ED}_{50} \cong 6.8 \mathrm{ng} / \mathrm{ml}$ $(1.1 \mathrm{nM})$.

response of control strips that were not treated with EGF-URO (Fig. $5 H$ ). In summary, EGF-URO markedly inhibited the NEmediated contraction of canine coronary artery helical strips. This inhibition was observed both in $\mathrm{Ca}$-containing and in $\mathrm{Ca}$ free medium and was also observed when NE-mediated contraction was made dependent on the addition of $\mathrm{Ca}$ to the organ bath.

\section{Discussion}

Our data document a potent vasodilatory action of EGF-URO that most likely results from a direct action of EGF-URO on arterioles. Characteristically, the time course of the response to EGF-URO (maximum at 2-6 min, persisting for up to $18 \mathrm{~min}$ ) differed markedly from the time course of the response to other agonists such as isoproterenol and sodium-nitroprusside, which caused a rapid response lasting $<1 \mathrm{~min}$. This observation suggests that EGF-URO probably does not act via the same pathways as these agonists. An effect of EGF-URO on nonmuscle cells (e.g., endothelial cells or neuronal elements) to release a vasodilatory substance responsible for the increased blood flow cannot be entirely ruled out. However, the information obtained with the pharmacologic blocking agents indicated that the vasodilatory action of EGF-URO did not appear to result secondarily from the release of known smooth muscle agonists (adrenergic, cholinergic, histaminergic, or purinergic) or from the release of endorphins or prostaglandins. In the experiments done in vitro
EGF-URO did not cause a direct relaxation of canine vascular strips but inhibited the contractile effects of NE, when applied to the tissue before (but not after) the administration of NE. This inhibition of the response to NE was independent of the presence of functional endothelium, suggesting that in vitro EGFURO exerts its effect directly on the smooth muscle cells rather than via the endothelium. Thus, our data suggest that the vasodilatory response to EGF-URO is mediated via EGF-URO receptors present in the smooth muscle itself. Such receptors have previously been detected in cultures of arterial smooth muscle (15).

We (7) and others (8) have observed that EGF-URO causes contraction of rat vascular strips in vitro. One might therefore have expected that EGF-URO administered to the intact dog would decrease regional blood flows. Yet, in the dog, in vivo, we observed an increase in flow. The in vitro observations in the dog coronary artery are, however, in keeping with the in vivo observations in that species.

In contrast with the studies with rat tissue, EGF-URO did not cause a contraction of isolated canine coronary arterial strips. Rather, it was a potent inhibitor of the contractile response to $\mathrm{NE}$. The differences between the in vitro data in the dog and rat may signal species differences in the response to EGF-URO and taken together, our data suggest: (a) that information obtained with rat vascular strips cannot be used to predict the responsiveness to EGF-URO of the vasculature of other species; and (b) that the effects of EGF-URO on blood flow in the dog arterial beds may result from its ability to modulate the resting vascular tone maintained by other agonists such as NE. The differential effects of EGF-URO in different vascular beds may, therefore, depend on the ambient autonomic tone in each bed. Because of a lack of knowledge of the precise dilution factor for the EGFURO administered in vivo, it is not possible to compare directly the dose-response curves obtained in vivo with those obtained in vitro. Nonetheless, assuming a further 20-50-fold dilution of the dose administered in vivo, one can calculate that the concentration at the site of the resistance vessels would be in the nanomolar range, in keeping with the concentration range for the action of EGF-URO in vitro. It is also important to keep in mind that the arterial strips used for the studies in vitro were obtained from the relatively large conductance vessels and not from the much smaller calibre downstream vessels that determine vascular resistance and blood flow in vivo. Thus, the data obtained with the strips in vitro need not necessarily reflect exactly the actions of EGF-URO on the more distal resistance vessels in vivo.

In terms of responsiveness towards EGF-URO (Table II), the arterial beds were distinct both in terms of maximum flow increase (high response: femoral and superior mesenteric; low response: carotid, coronary, celiac, and renal) and in terms of the sensitivity $\left(\mathrm{ED}_{\mathbf{5 0}}\right)$ towards EGF-URO (low ED $\mathrm{ED}_{50}$ : femoral, superior mesenteric, carotid, and coronary; high $\mathrm{ED}_{50}$ : celiac and renal). Because there was no correlation between maximum responsiveness and sensitivity $\left(E D_{50}\right)$, it was difficult to attach any mechanistic significance to these differences in the arterial responses. Further, in that arterial strips derived from the femoral artery were as responsive (maximum inhibition of agonist-mediated contraction) towards EGF-URO as were the coronaryderived strips, there did not appear to be a simple correlation between the responsiveness of the resistance vessels and the responsiveness of the larger conductance vessels. 
Table II. Calculated $E D_{50}$ and $E_{\max }$ for EGF-URO in the Various Vascular Beds Tested

\begin{tabular}{lll}
\hline Arterial bed & $E_{\max }$ & ED $_{\text {so }}$ \\
\hline$(n)$ & \% increase in flow & $\mu g$ EGF-URO \\
Femoral (12) & 70 & 0.4 \\
Superior mesenteric (9) & 65 & 0.4 \\
Carotid (4) & 20 & 0.4 \\
Coronary (5) & 15 & 0.4 \\
Celiac (5) & 15 & 0.9 \\
Renal (5) & 15 & 0.9 \\
\hline
\end{tabular}

The dose-response curves like those illustrated in Figs. 2 and 4 were linearized using a double-reciprocal plot, as outlined in the text and in the legend to Fig. 3. Values for the $\mathrm{ED}_{50}$ and $E_{\max }$ were estimated from the reciprocals of the $x$ - and $y$-intercepts, respectively. The numbers in parentheses represent the number of animals used to investigate the respective vascular beds.

Of interest is the observation that the vasodilatory action of EGF-URO in the dog was not reversed by indomethacin $(5 \mathrm{mg}$ / $\mathrm{kg}$ ); in contrast indomethacin did abolish the contractile effect of EGF-URO in the rat tissue (7). The data suggest that the action of EGF-URO in the dog vasculature, in contrast with its actions in other tissues $(7,16-18)$ is not mediated via products of the cyclooxygenase pathway. This conclusion is also supported by the data obtained in vitro, where the ability of EGF-URO to inhibit NE-mediated contraction was not affected by indomethacin $(3 \mu \mathrm{M})$.

Both the blood flow response and the agonist-inhibitory action of EGF-URO in vitro exhibited tachyphylaxis. However, the reduced response to EGF-URO observed in vivo, either upon repeated administration or upon constant infusion (Fig. 1) could be overcome by lengthening the dose interval. The return of responsiveness in vivo may have been due to the constant perfusion of the tissue during the time period of tissue response. In contrast, the tachyphylaxis observed for the strips in vitro was not readily reversed. This tachyphylaxis phenomenon would be of importance in vivo where the release of EGF-URO from platelets or from tumors (see below) might cause only a transient response of the vasculature. In this regard it is of considerable interest that preliminary data obtained with transforming growth factor-alpha ( $\alpha$-TGF) indicate that the EGF-URO-related polypeptide does not cause tachyphylaxis in terms of the vascular response (19). Further work is thus warranted to examine the mechanism of vascular tachyphylaxis towards EGF-URO.

In the literature there are conflicting reports of the effects of EGF-URO on the intracellular free calcium concentration. Several reports indicate either a stimulation of ${ }^{45} \mathrm{Ca}$ efflux, which is associated with an increase in intracellular $\mathrm{Ca}(8,17,20-22)$, or a direct increase in intracellular $\mathrm{Ca}$ as measured with fluorescent $\mathrm{Ca}$ indicators (23-25). Other reports, however, could not detect an influence of EGF-URO either on ${ }^{45} \mathrm{Ca}$ efflux (26) or on intracellular free $\mathrm{Ca}$ measured with the fluorescent $\mathrm{Ca}$ indicators (27). Because it is generally accepted that an increase in smooth muscle intracellular $\mathrm{Ca}$ is associated with an increase in muscle tension (and thus vasoconstriction), it is of interest that we did not find either a direct contraction or a direct relaxation of canine coronary arterial strips in response to EGF-URO; rather we observed an inhibition of NE-mediated contraction. A similar in- hibitory effect of EGF-URO can be observed in canine arterial tissue (superior mesenteric) contracted either by transmural electrical stimulation or by $\mathrm{KCl}(28)$. The action of EGF-URO on tissues stimulated by transmural electrical stimulation probably reflects more accurately the situation in vivo. Evidently, EGF-URO may be able to reverse the effects of intermittent pulses of neurotransmitter released in intact tissue, whereas it cannot reverse the effect of constant exposure of the tissue to an agonist like NE applied in vitro. The inhibition of NE-mediated contraction was observed in strips equilibrated either in a Ca-free medium or in a Ca-containing medium (Fig. 5). Taken together, these data suggest that EGF-URO in canine vascular tissue probably does not act per se as a regulator of intracellular calcium concentration. Thus, whatever the mechanism whereby EGF-URO affects the canine vascular tissue, it would appear to differ from mechanisms suggested to date that focus on the ability of EGF-URO to raise intracellular calcium (29), thereby causing hyperpolarization via a $\mathrm{Ca}^{2+}$-dependent $\mathrm{K}^{+}$channel (30). It is attractive to suggest that EGF-URO without regulating calcium levels directly, might interfere with the biochemical steps triggered by calcium to contract smooth muscle cells. One is not able however, on the basis of our experiments, to rule out the possibility that EGF-URO might interact with the mechanisms whereby an agent like NE raises intracellular calcium (Ca channel activation or mobilization of intracellular stores via inositol trisphosphate) so as to have an indirect effect on cytoplasmic calcium levels. More experiments to determine the exact mode of action of EGF-URO in the canine arterial strips will be necessary. Presumably, mechanisms akin to the ones mediating the action of EGF-URO on the arterial strips in vitro may also be found to be responsible for the action of EGF-URO on the smaller resistance vessels that control blood flow in vivo.

It is an open question as to whether or not EGF-URO may play a meaningful physiological role in regulating regional blood flow in vivo. Although EGF-URO is presumed to be present in the circulation of the dog, there are as yet no good estimates of plasma levels in this species because of a lack of a suitably sensitive assay for canine EGF-URO. From serum levels estimated either in the mouse or in humans ( $1 \mathrm{nM}$ or lower $[31,32])$ it would appear unlikely that plasma EGF-URO per se might play a role in the minute-to-minute regulation of regional blood flow. Nonetheless, the effects of EGF-URO on blood flow take on added significance in view of the occurrence of either EGFURO or the EGF-URO-related polypeptides (so-called $\alpha$-transforming growth factors or $\alpha$-TGFs) in platelets (33) and in view of the production of these factors by tumors $(34,35)$. Thus, it is possible that the physiological role for EGF-URO may be found in relation to the release by platelets of vasoactive cell regulators like EGF-URO $(7,8)$ and platelet-derived growth factor (27). Even more intriguing is the possibility that tumors can produce either EGF-URO (34) or the closely related $\alpha$-TGFs $(34,35)$. It is known that $\alpha$-TGFs acting via the EGF-URO receptor can trigger the same cellular responses caused by EGFURO $(34,35)$. This opens the exciting possibility that tumors, by secreting EGF-URO-related $\alpha$-TGFs in a paracrine manner and acting via the EGF-URO receptor, may be able to regulate their own blood flow and, via this system, contribute to the local vascular hyperdynamic state associated with malignancy. Clearly, further studies on the responsiveness of arterial tissue derived from both humans and other species to EGF-URO and the EGFURO related $\alpha$-TGFs appear warranted. 


\section{Acknowledgments}

We are indebted to Mr. M. Tiffany for his skilled technical assistance and to Dr. G. R. Bolt for helpful discussions. We are very grateful to Mrs. J. Gayford for preparing this manuscript.

This work was supported in part by grants from the Canadian Medical Research Council (to Drs. Hollenberg and MacCannell), the Canadian Heart Foundation (to Dr. MacCannell), and the Netherlands Heart Foundation (to Dr. Gan, M.D.). Dr. Gan is the recipient of a studentship award from the Alberta Heritage Foundation for Medical Research.

\section{References}

1. Carpenter, G., and S. Cohen. 1979. Epidermal growth factor. Annu. Rev. Biochem. 48:193-216.

2. Gregory, H., J. M. Bower, and I. R. Willshire. 1977. Urogastrone and Epidermal Growth Factor. In Growth Factors. K. W. Kastrup and J. H. Nielsen, editors. FEBS (Fed. Eur. Biochem. Soc.) Colloquium B3. 48:75-84.

3. Hollenberg, M. D. 1979. Epidermal growth factor-urogastrone: a polypeptide acquiring hormonal status. Vitam. Horm. 37:69-110.

4. Carpenter, G. 1981. Tissue growth factors. In Handbook of Experimental Pharmacology. Vol. 57. R. Baserga, editor. Springer-Verlag, Berlin, Heidelberg, New York. 89-132.

5. Carpenter, G., and J. G. Zendegui. 1986. Epidermal growth factor, its receptor and related proteins. Exp. Cell. Res. 164:1-10.

6. Scoggins, B. A., A. Butkus, J. P. Coghlan, D. T. W. Fei, J. G. McDougall, H. D. Niall, and X.-M. Wang. 1984. In-vivo cardiovascular, renal and endocrine effects of epidermal growth factor in sheep. In Abstracts of the 7th International Conference of Endocrinology. Excerpta Medica, Amsterdam. 124.

7. Muramatsu, I., M. D. Hollenberg, and K. Lederis. 1985. Vascular actions of epidermal growth factor-urogastrone: possible relationship to prostaglandin production. Can. J. Physiol. Pharmacol. 63:994-999.

8. Berk, B. C., T. A. Brock, R. C. Webb, M. B. Taubman, W. J. Atkinson, M. A. Gimbrone, Jr., and R. W. Alexander. 1985. Epidermal growth factor, a vascular smooth muscle mitogen, induces rat aortic contraction. J. Clin. Invest. 75:1083-1086.

9. Savage, C. R., Jr., and S. Cohen. 1972. Epidermal growth factor and a new derivative. J. Biol. Chem. 247:7609-7611.

10. Hollenberg, M. D., and H. Gregory. 1980. Epidermal growth factor-urogastrone: biological activity and receptor binding of derivatives. Mol. Pharmacol. 17:314-320.

11. MacCannell, K. L., and K. Lederis. 1977. Dilatation of the mesenteric vascular bed of the dog produced by a peptide, urotensin I. J. Pharmacol. Exp. Ther. 203:38-46.

12. MacCannell, K. L., P. L. Hamilton, K. Lederis, C. A. Newton, and J. Rivier. 1984. Corticotropin releasing factor-like peptides produce selective dilatation of the dog mesenteric circulation. Gastroenterology. 87:94-102.

13. Charbon, G. A., and F. van der Mark. 1981. Use of electromagnetic flowmeters for the study of splanchnic blood flow. In Measurement of Blood Flow. Applications to the Splanchnic Circulation. D. N. Granger and G. B. Bulkley, editors. Williams \& Wilkins Co., Baltimore, MD. 125-155.

14. VanHoutte, P. M., G. M. Rubanyi, V. M. Miller, and D. S. Houston. 1986. Modulation of vascular smooth muscle contraction by the endothelium. Annu. Rev. Physiol. 48:307-320.

15. Bhargava, G., L. Rifas, and M. H. Makman. 1979. Presence of epidermal growth factor receptors and influence of epidermal growth factor on proliferation and aging in cultured smooth muscle cells. J. Cell Physiol. 100:265-374.

16. Voelkel, E. F., A. H. Tashjian, Jr., and L. Levine. 1980. Cycloox- ygenase products of arachidonic acid metabolism by mouse bone in organ culture. Biochim. Biophys. Acta. 620:418-428.

17. Shupnik, M. A., and A. H. Tashjian, Jr. 1982. Epidermal growth factor and phorbol ester actions on human osteosarcoma cells. J. Biol. Chem. 257:12161-12164.

18. Chiba, T., Y. Hirata, T. Taminato, S. Kadowaki, S. Matsukura, and T. Fujita. 1982. Epidermal growth factor stimulates prostaglandin $\mathrm{E}$ release from isolated perfused rat stomach. Biochem. Biophys. Res. Commun. 105:370-374.

19. Gan, B. S., M. D. Hollenberg, K. L. MacCannell, M. Winkler, and R. Derynck. 1986. Distinct vascular actions of epidermal growth factor-urogastrone and $\alpha$-transforming growth factor. Clin. Res. 34:629A. (Abstr.)

20. Chinkers, M., J. A. McKanna, and S. Cohen. 1981. Rapid rounding of human epidermoid carcinoma cells A-431 induced by epidermal growth factor. J. Cell. Biol. 88:422-429.

21. Owen, N. E., and M. L. Villeral. 1983. Efflux of ${ }^{45} \mathrm{Ca}^{2+}$ from human fibroblasts in response to serum or growth factors. J. Cell. Physiol. 117:23-29.

22. Sawyer, S. T., and S. Cohen. 1981. Enhancement of calcium uptake and phosphatidylinositol turnover by epidermal growth factor in A-431 cells. Biochemistry. 20:6280-6286.

23. Morris, J. D. H., J. C. Metecalfe, G. A. Smith, T. R. Hesketh, and M. V. Taylor. 1984. Some mitogens cause rapid increases in free calcium in fibroblasts. FEBS (Fed. Eur. Biochem. Soc.) Lett. 169:189193.

24. Moolenaar, W. H., L. G. J. Tertoolen, and S. W. de Laat. 1984. Growth factors immediately raise cytoplasmic free $\mathrm{Ca}^{2+}$ in human fibroblasts. J. Biol. Chem. 259:8066-8069.

25. Hesketh, T. R., J. P. Moore, J. D. H. Morris, M. V. Taylor, J. Rogers, G. A. Smith, and J. C. Metcalfe. 1985. A common sequence of calcium and $\mathrm{pH}$ signals in the mitogenic stimulation of eukaryotic cells. Nature (Lond.). 313:481-484.

26. Lopez-Rivas, A., and E. Rozengurt. 1983. Serum rapidly mobilizes calcium from an intracellular pool in quiescent fibroblastic cells. Biochem. Biophys. Res. Commun. 114:240-247.

27. Berk, B. C., R. W. Alexander, T. A. Block, M. A. Gimbrone, Jr., and R. C. Webb. 1986. Vasoconstriction: A new activity for plateletderived growth factor. Science (Wash. DC.). 232:87-90.

28. Muramatsu, I., M. D. Hollenberg, and K. Lederis. 1986. Modulation by epidermal growth factor-urogastrone of contraction in isolated canine helical mesenteric arterial strips. Can. J. Physiol. Pharmacol. 64: 1561-1565.

29. Macara, I. G. 1986. Activation of ${ }^{45} \mathrm{Ca}^{2+}$ influx and ${ }^{22} \mathrm{Na}^{+} / \mathrm{H}^{+}$ exchange by epidermal growth factor and vanadate in A431 cells is independent of phosphatidylinositol turnover and is inhibited by phorbol ester and diacylglyerol. J. Biol. Chem. 261:9321-9327.

30. Enomoto, K.-I., M. F. Cossu, T. Maeno, C. Edwards, and T. Oka. 1986. Involvement of the $\mathrm{Ca}^{2+}$-dependent $\mathrm{K}^{+}$channel activity in the hyperpolarizing response induced by epidermal growth factor in mammary epithelial cells. FEBS (Fed. Eur. Biochem. Soc.) Lett. 203: 181-184.

31. Byyny, R. L., D. N. Orth, S. Cohen, and E. S. Doyne. 1974. Epidermal growth factor: effects of androgens and adrenergic agents. Endocrinology. 95:776-782.

32. Gregory, H., S. Walsh, and C. R. Hopkins. 1979. The identification of urogastrone in serum, saliva, and gastric juice. Gastroenterology. 77:313-318.

33. Oka, Y., and D. N. Orth. 1983. Human plasma epidermal growth factor/ $\beta$-urogastrone is associated with blood platelets. J. Clin. Invest. 72:249-259.

34. Stoscheck, C. M., and L. E. King, Jr. 1986. Role of epidermal growth factor in carcinogenesis. Cancer Res. 46:1030-1037.

35. Goustin, A. S., E. B. Leof, G. D. Shipley, and H. L. Moses. 1986. Growth factors and cancer. Cancer Res. 46:1015-1029. 